\title{
A study on Strengthening of Building foundation for Storey Extension
}

\author{
Zumrawi M. M. E. ${ }^{1,}{ }^{*}$, Aldaw H. K. E. ${ }^{2}$
}

\begin{abstract}
1,* Department of Civil Engineering, Faculty of Eng., University of Khartoum, Khartoum, Sudan.
2 Department of Civil Engineering, Faculty of Eng., University of Khartoum, Khartoum, Sudan.

* Corresponding Author: magdi.zumrawi@yahoo.com
\end{abstract}

Received: 23-06-2018

Revised: $24-10-2018$

Accepted: 28-10-2018

\begin{abstract}
Storey extensions are an increasingly popular way to crowded cities. Lack experience and knowledge concerning strengthening of structures are major challenges for engineers. This paper presents strengthening practice adopted for foundations of existing building when storey extension is needed. Literature concerning strengthening techniques commonly adopted and some historical cases were reviewed. A complex hall building in university of Khartoum which was rehabilitated in 2009 by strengthening the structural members of the existing building to accommodate additional floors was undertaken as a case study. The records and reports of the original design and last rehabilitation of the building were reviewed. Field inspection of the building condition before rehabilitation was carried out. The study results showed that the appropriate design, the strengthening materials used and the procedure followed are the key factors for economical and successful strengthening.
\end{abstract}

Key words: Storey extension, foundation, Strengthening technique, rehabilitation.

\section{Introduction}

Capacity enhancement of foundations may be required to accommodate additional loads during expansion of existing structures. To achieve this, effective approaches to strengthen existing foundations are of paramount concern in engineering practice (Bian et al., 2006). In fact, strengthening practice is necessary when replacing existing buildings with higher or denser ones, changing building functions or internal apartment arrangements to enable more people to live in already built structures, or vertically extend already existing buildings. The latter approach is the one that has been considered in this study (Johansson and Thyman, 2013).

When new floors are added, the building will be subjected to higher loads both vertically and horizontally. These must in some way safely be transferred downwards through the superstructure to the foundation. In some cases there is an excess capacity of the existing building and its foundation, but if the capacity is too low, it might sometimes be necessary to strengthen the existing structure and its foundation (Islam and Qaiyum, 2013).

The main focus of this study is strengthening of pad foundations of existing buildings for story extension. The paper reviews the most common and efficient strengthening techniques that can be used for reinforced concrete structures.

\section{Literature review}

\subsection{General}

Strengthening and repair of any structure are commonly used in rehabilitation process. Strengthening is a method used to improve the structural stability of a building to accommodate additional load, this enables the use of the building for intended purpose. In case of a damaged or deteriorated reinforce concrete element, strengthening must be associated with structural repair (Islam and Qaiyum, 2013). The need to strengthen a structure may be required at any 
time from the beginning of the construction phase until the end of the building service. During the construction phase may occur deficient in concrete production, errors in the design or bad execution processes, while during the service life, it may arise on account of earthquake, changing in the structure functionality, developing of more demanding code requirements and damaging of structure by an accident, such as collisions, fire, explosions (Branco and Silva, 2003).

The selection of strengthening system depend on many technical factors including serviceability, strength, durability and non-technical factors such as constructability, aesthetics and cost/ benefit analysis. The latter one is paramount principle to determine the most effective and economical strengthening methods among the alternative options (Rodriguez and Park, 1991). In most cases with any of the selected strengthening system, there is also an associated increase in the stiffness of the structure. Caution must be taken to avoid an irregular stiffness distribution in the strengthened structure (Rodriguez and Park, 1991).

\subsection{Strengthening concrete structures}

Most strengthening techniques used for concrete structures are based on the assessment of engineers only and, often empirical knowledge and current practice have an important role in the decisions to be made, materials and approaches used to strengthen reinforce concrete structures mostly are independent of which structural member to be treated. There are mainly three different techniques when strengthening a structural element; Sectional enlargement with additional reinforced or plain concrete, strengthening with externally mounted steel and strengthening with fiber reinforced polymers (Johansson and M. Thyman, 2013).

Sectional enlargement with additional reinforced or plain concrete is one of the simplest way for strengthen concrete members. It aims to increase the thickness of the member. However, there are some important aspects considered, when fresh concrete is applied to old. To achieve good bond the old surface must be roughened and cleaned. Sometimes epoxy glue might be useful to further strengthen the bond. If the shear forces at the joint interface are significant, additional anchors in the shape of bolts or stirrups might be needed as well (Statens råd, 1978).

Regular reinforcement bars can be used in the added concrete, when performing a section enlargement on a member. Also, steel can be mounted externally by means of sheets and profiles or apply a prestressing force (Nordin, 2005). It is important to attach them and achieve interaction with the concrete. However, the durability problem exhibited by steel in form of corrosion can affect the bond between the plate and the concrete (Norris et al., 1997).

Fiber reinforced polymers (FRP) is a composite material consisting of fibers surrounded by a polymer matrix. The matrix is what keeps the fibers together and transfers the forces between the individual fibers. The matrix also acts as protection for the fibers. Different materials can be used as matrix, but epoxy based is the most commonly used. The main types of fibers are Carbon, glass, and aramid (Carolin, 2003). All fibers behave elastically until a brittle failure and normally have a higher tensile strength than steel. Carbon fibers have several benefits in a structural context such as its high strength to weight ratio and high modulus of elasticity (Cozmanciuc et al., 2009). Carbon fibers are therefore the most common type used when strengthening buildings.

\subsection{Previous experiences on strengthening}

Several researches have been conducted on strengthening of structural members. Islam and qaiyum (2013) performed some analytical analysis for structural elements. Models were first submitted to structural elements before extension, then for the future anticipated load, the results show that the column and foundation were not capable to carry extra load from additional storey as the design vertical load for four storeys exceeded the load carrying capacity 
of the element and hence, strengthening is required for column and foundation. Also, they stated that both the Reinforced Concrete (RC) jacketing and FRP could increase the capacity of column, but the cost analysis shows that the total cost of RC jacketing to be about $15 \%$ the FRP strengthen cost. Besides this, the installation cost is also high for FRP strengthening and for the foundation strengthening the enlargement of the section was used, and the required size was measured to carry the additional loads safely (Islam and qaiyum, 2013).

Johansson and Thyman (2013) studied strengthening of a foundation with different techniques when six storeys were added. The building in Goteborg region in Turkey is founded in a deep layer of clay and the original foundation was performed with $18 \mathrm{~m}$ long timber trunks as cohesion end-bearing piles that rest on the bedrock piles. From the new design it was found that the piles and soil could take the increased load, but the pile caps were too weak. To shift the new load from the pile cap, it was decided to strengthen the foundation with winged steel piles as illustrated in Fig 1. The VKR-profiles were prestressed to ensure that the winged steel piles were loaded immediately. Many of the columns also needed to increase their capacity by section enlargement with self-compacting concrete to ensure proper filling. The increased area of the column reduces the local shear force per unit width on the pile cap.
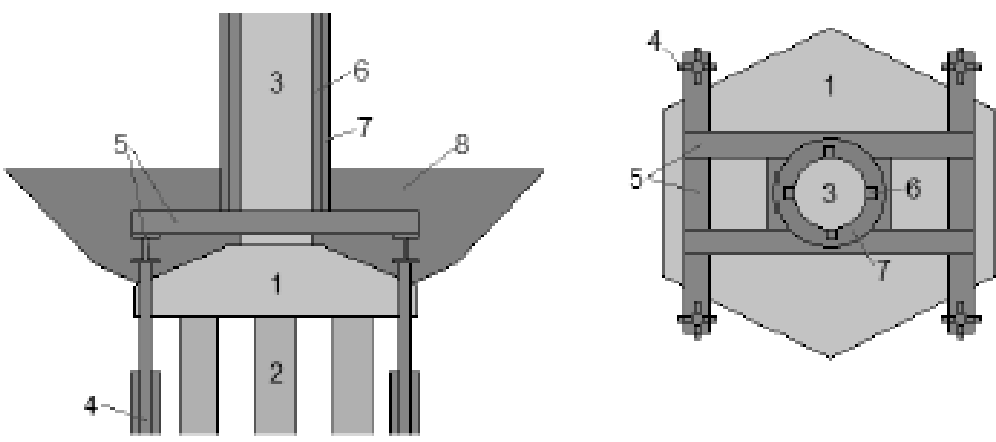

1) Original pile cap 2) Original timber piles 3) Original column 4) New winged piles 5) Steel beams 6) Prestressed VKR-profiles 7) New layer of concrete 8) New layer of concrete

Fig 1. Illustration of how the foundation was strengthened Johansson and Thyman (2013).

Shihada and Al-Jerjawy (2011) assessed a sixteen-storey building in Gaza which damaged by air attack in 2009. They considered the option of repair and strengthening of the building than demolition and rebuilding. Design checks for slab, column, shear wall and mat foundation were carried out. Moreover, soil pressures under the mat before and after the incurred damage were evaluated. The results showed that the design of all structural elements of the building is satisfactory. The soil pressure under the mat is within the allowable bearing capacity of the soil. Based on the assessment results by computer software modeling for the damaged structural members, the columns showed minor damage were repaired by straightened or tied the existing bars with new bars of the same diameter if they were cut then patching new concrete cast on them. The columns showing major cracking, they were strengthening by RC jacketing.

\section{Case study}

The current investigation was carried out on a selected project in Khartoum. This project was redesigned to accommodate additional floor for the existing building. The investigation consisted of field survey of the site condition and data collection about the design and any other information assist in investigation. The site visual inspection and photographs taken for the foundation of the building were used to assist in diagnosis the current condition. The case selected for this study is located at university of Khartoum in Khartoum.

\subsection{Project description}

Complex hall lecture, located in the main campus of university of Khartoum, was built in 2007 and initially reached $8 \mathrm{~m}$ height above the ground. The building consists mainly of a big hall in the ground floor with some rooms and a number of offices are located in the first floor. The 
building is a two-story reinforced concrete frame founded on footings in a sandy clay soil. The structural system consists of in-situ cast reinforced concrete columns, beams, slabs and isolated footings.

One new storey was added in 2009, giving the building a new height of $12 \mathrm{~m}$ as shown in Fig. 2 . The building original structural elements have been strengthened to be able to support the additional load of storey extension. The study was conducted to evaluate the new foundation design. The main feature of this design was enlarging the footing sections to increase their load carrying capacity to accommodate the additional load.

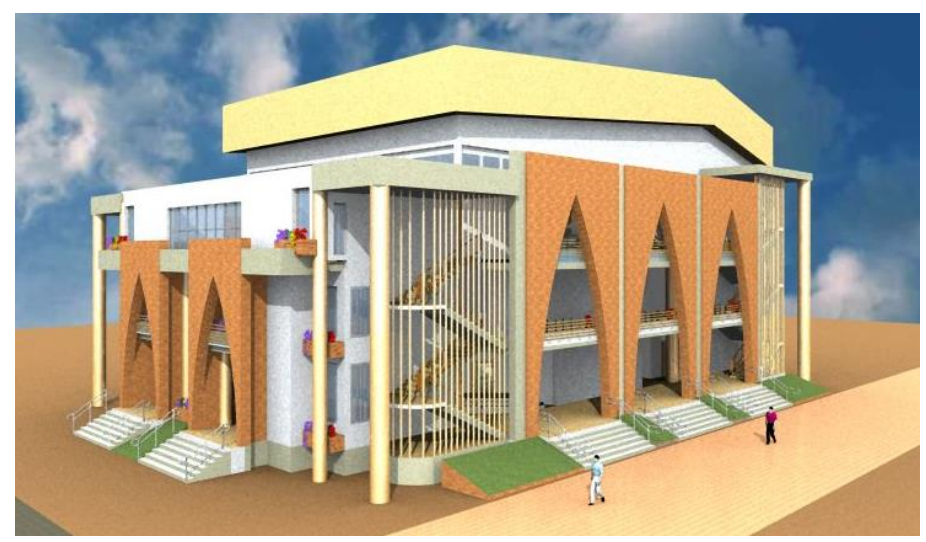

Fig 2. The building after storey extension.

\subsection{Foundation design}

The original design of the building was done by DAL Company and based on BS 8110 (1997). The plan area of the building, size and reinforcement of columns and foundations are shown in Figure 3 and Table 1.

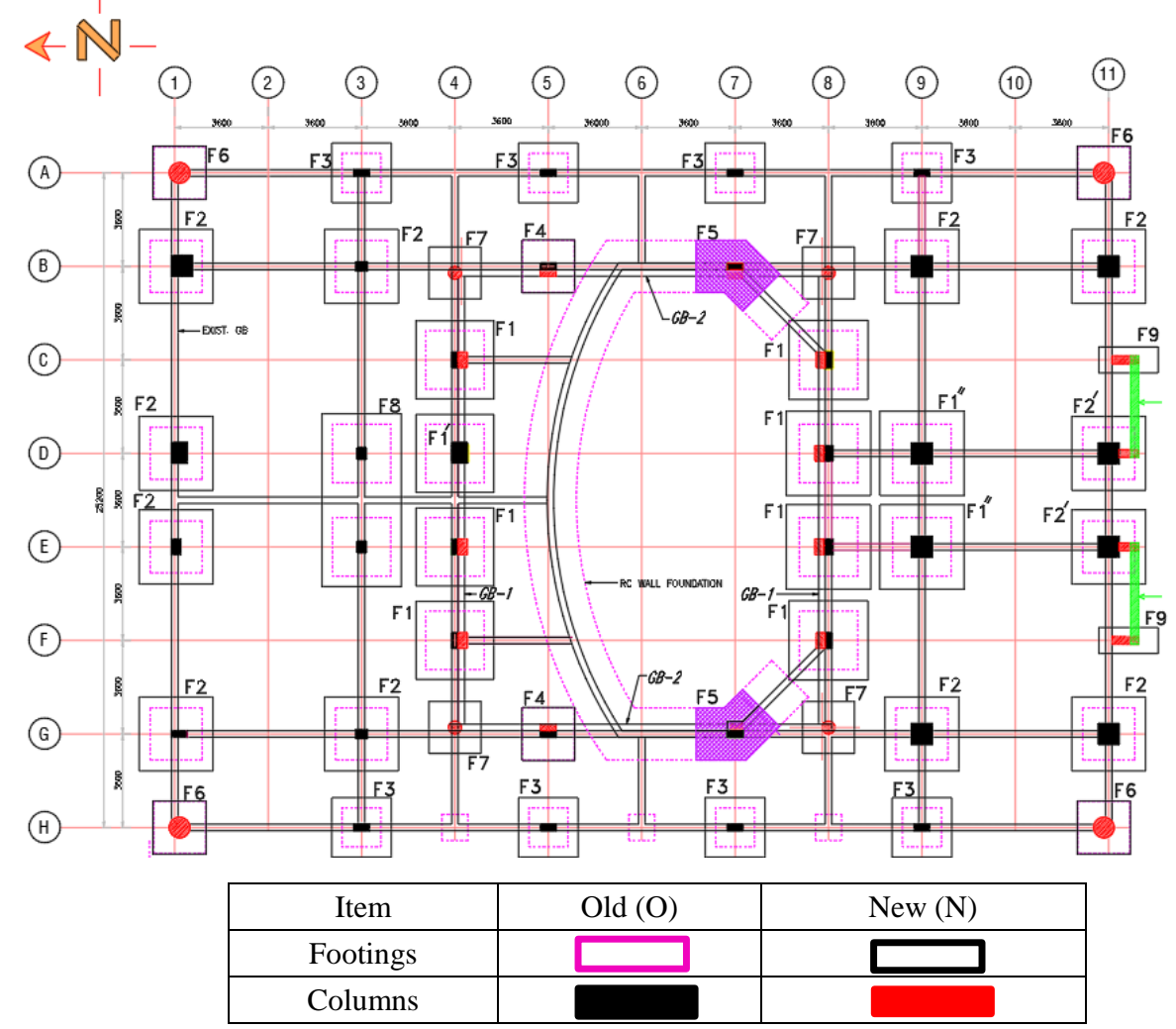

Fig 3. Layout plan of foundation. 
Table1. Result of original design for foundations.

\begin{tabular}{|c|c|c|l|}
\hline Footing & Quantity & Size & Reinforcement \\
\hline \hline F1 & 10 & $2.250 * 2.250 *(400-500)$ & T16@150 c/c B.W. \\
\hline F2 & 14 & $2.000 * 2.000 * 400$ & T16@150 c/c B.W. \\
\hline F3 & 12 & $1.500 * 1.500 * 300$ & T16@150 c/c B.W. \\
\hline F4 & 4 & $2.000 * 2.000 * 500$ & T16@150 c/c B.W. \\
\hline
\end{tabular}

In the new design a floor was added to the building to become three-storey reinforced concrete frame. The strengthening technique adopted is sectional enlargement for the existing footings. In this research, the new design for the footings of the building was carried out based on BS (1997). The results obtained of the new foundation design are given below in Table 2 .

Table 2. The result of the new foundation design

\begin{tabular}{|c|c|c|}
\hline Footing & Quantity & Size \\
\hline \hline F1, F1'\&F1" & 10 & $3.000 * 3.000 * 800$ \\
\hline F2, F2'\&F2" & 12 & $2.85 * 2.85 * 750$ \\
\hline F3 & 8 & $2.30 * 2.30 * 600$ \\
\hline F4 & 2 & $2.00 * 2.00 * 750$ \\
\hline F5 & 2 & (part of R.C wall footing) \\
\hline F6 & 4 & $2.00 * 2.00 * 750$ \\
\hline F7 & 4 & $2.00 * 2.00 * 600$ (new) \\
\hline F8 & 1 & $6.600 * 3.200 * 800$ (combined) \\
\hline F9 & 2 & $2.285^{*} 1.00 * 600$ (new) \\
\hline
\end{tabular}

\section{Footing strengthening guidelines}

These guidelines describe the procedure for footing strengthening by sectional enlargement. After adding a storey, the imposed load by the superstructure may exceed the capacity of the structure elements. As the design load exceeds the capacity, thus strengthening is required. Enlargement of the footing section is needed for increasing the capacity. The strengthening of the existing footings was done by enlarging their sections. The construction started by excavating the area around the footing to the required dimensions as shown in Fig 4.

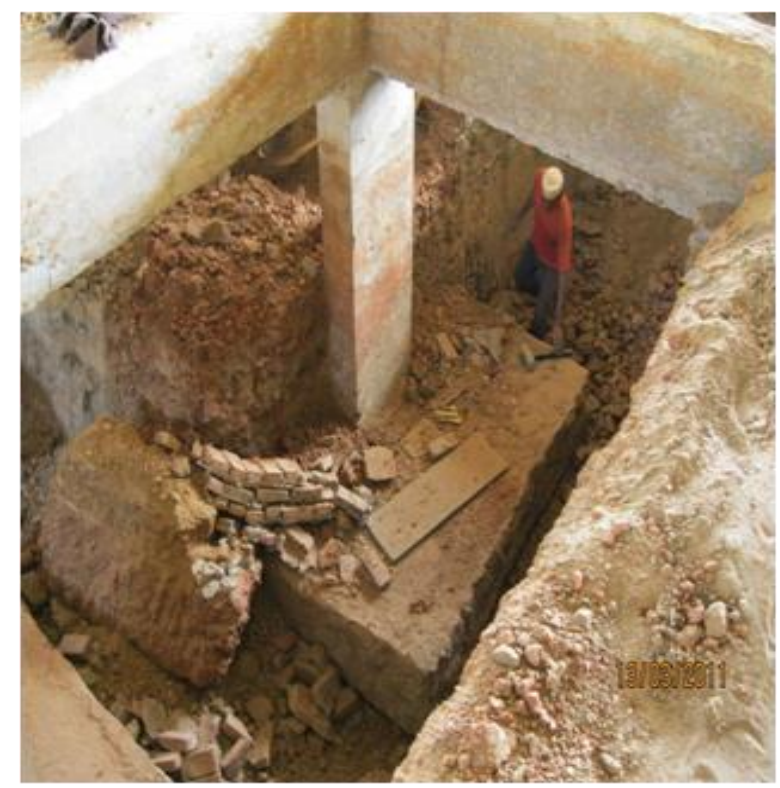

Fig 4. Excavation around the footing. 
Small holes were drilled with epoxy grout at the surface and sides of the footing. Then dowel bars were inserted in the drilled holes as shown in Fig 5.
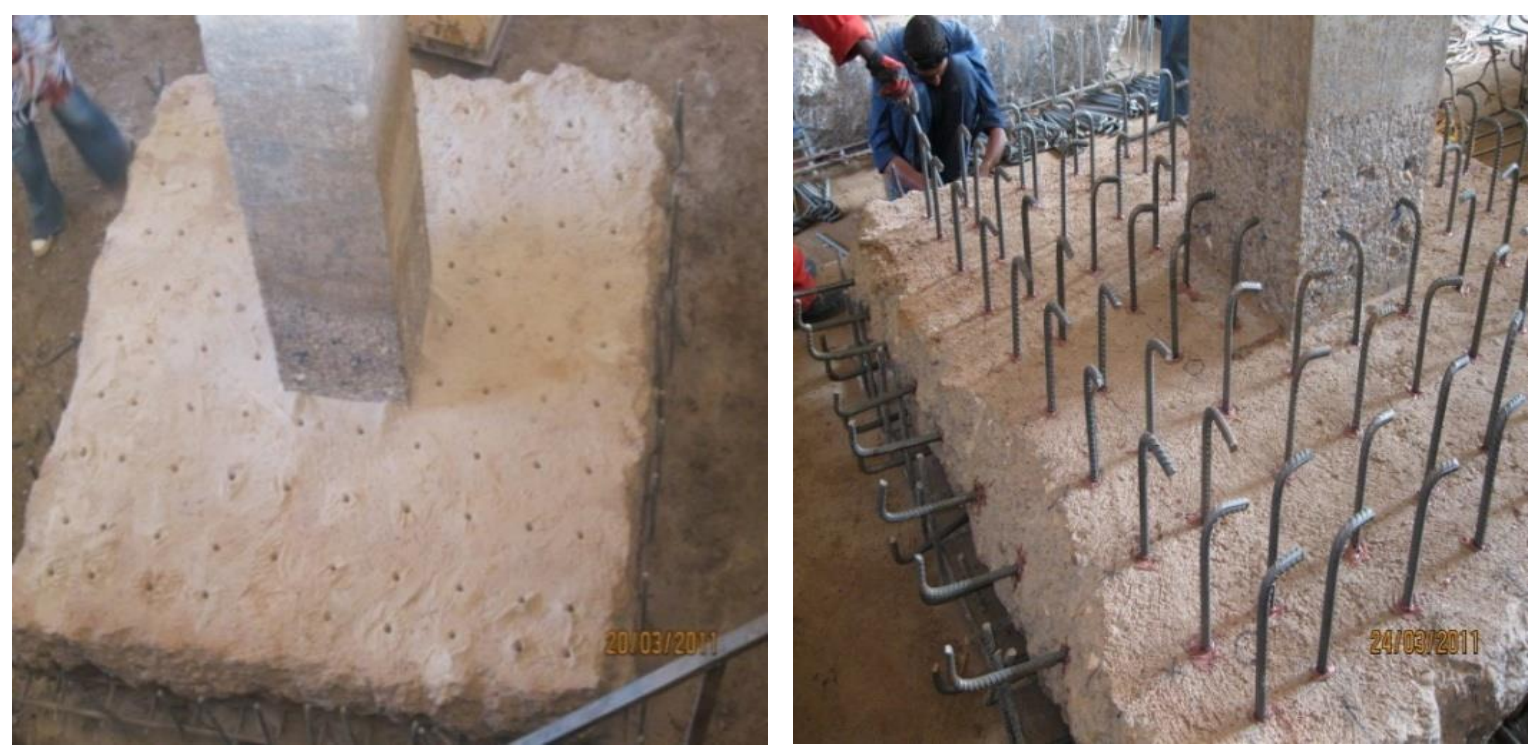

Fig 5. Drilled holes and inserted dowels bars.

Additional plain concrete of $10 \mathrm{~cm}$ thick was casted in the extended area of the footing before arranging the reinforcement bars surrounding the footing as shown in Fig. 6. The reinforcement of the enlarged footing is plotted in Fig. 7.
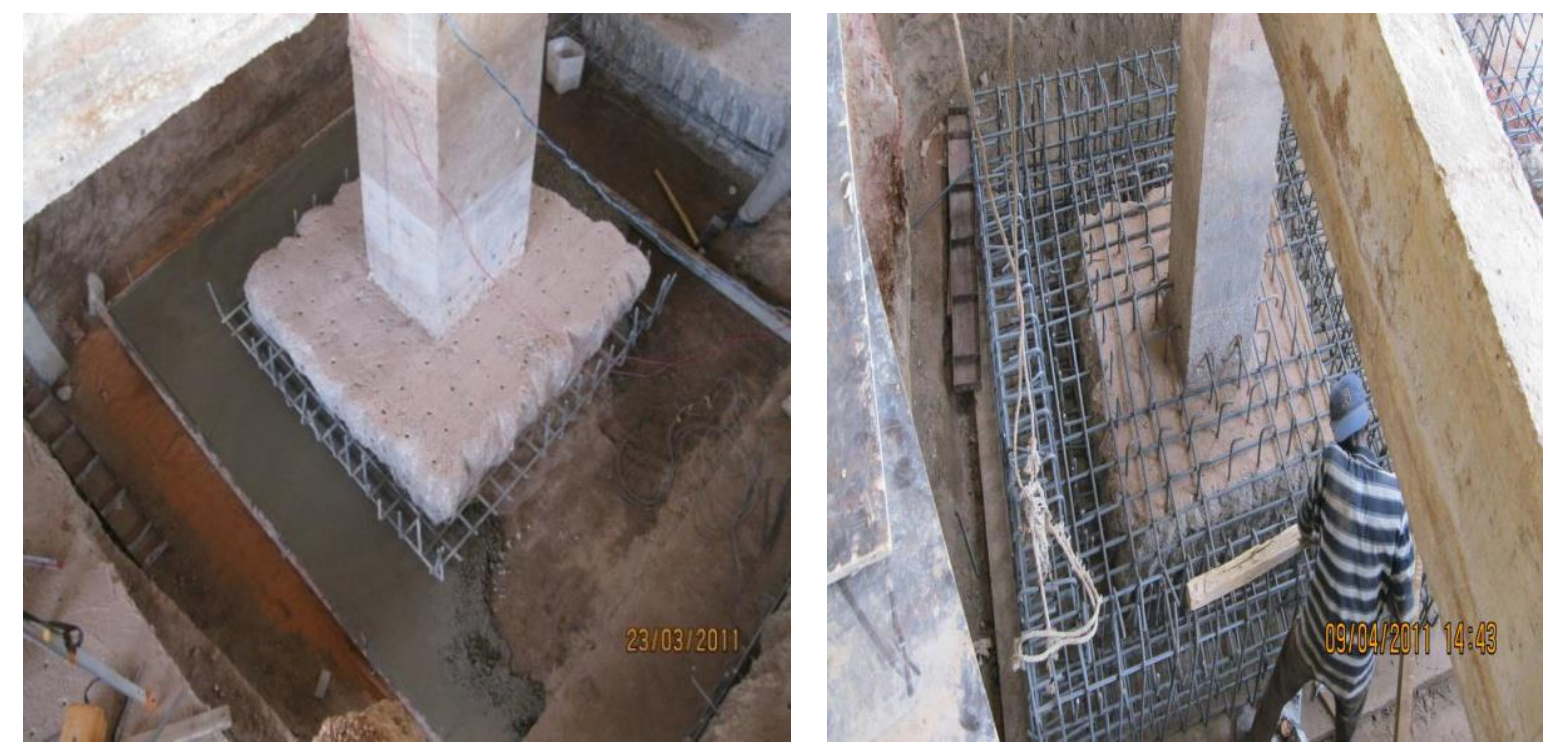

Fig 6. Plain concrete in the extended area and the reinforcement bars arranged surrounding the footing. 


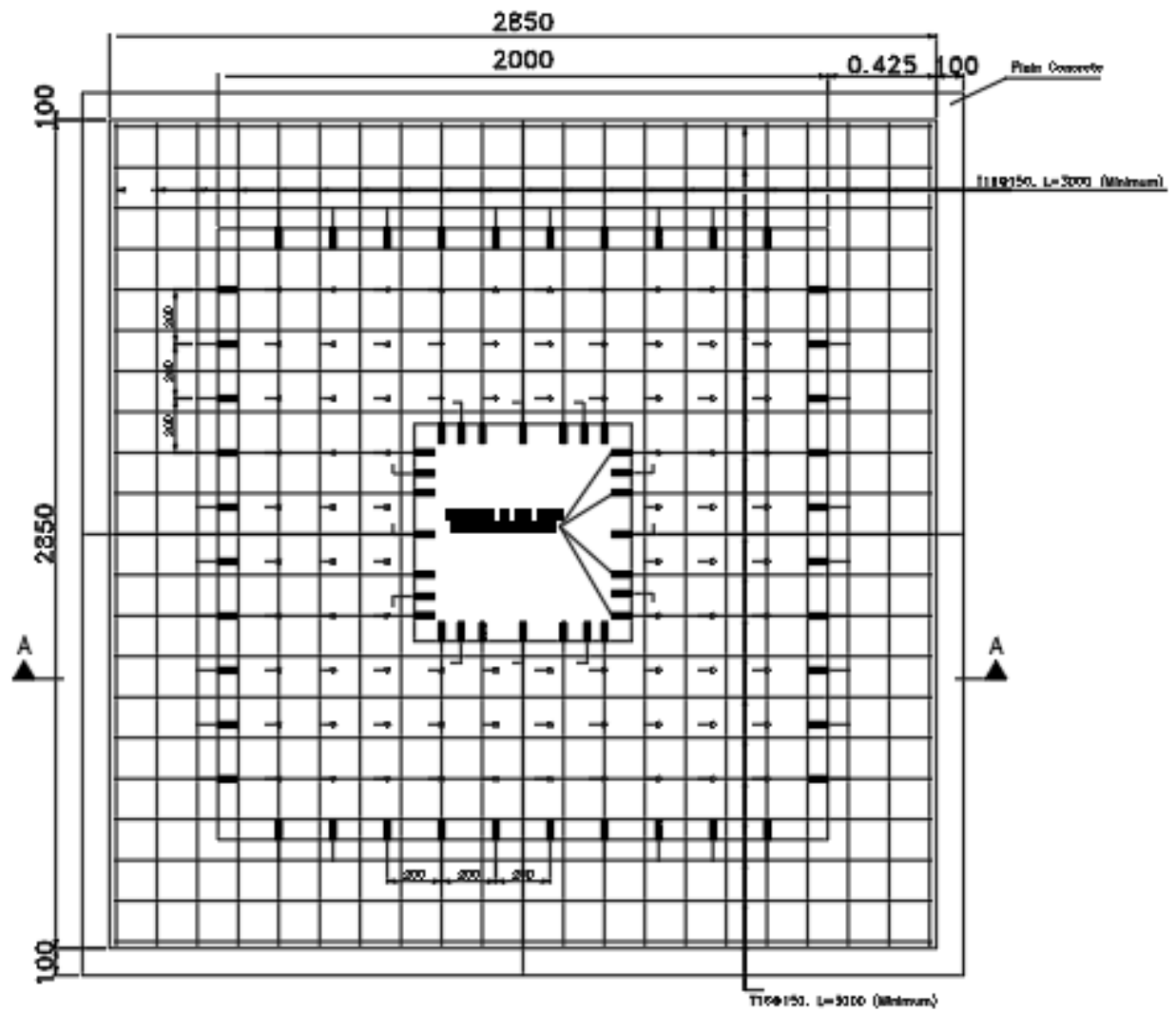

(a) Reinforcement plan

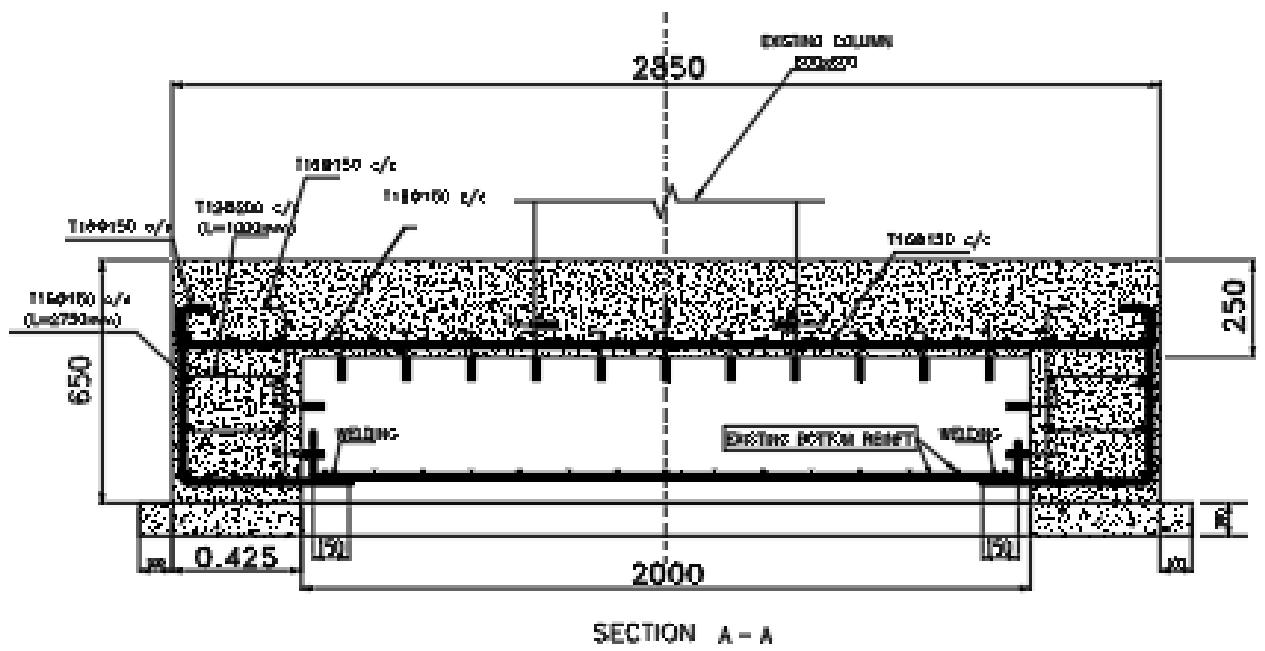

(b) Reinforcement cross-section

Fig 7. Reinforcement plan and cross-section of the footing enlarged area

Fresh concrete was casted with proper compaction to cover the enlarged area of the footing as shown in Fig. 8. Expanding agents must be added to the concrete mixture to ensure gab fillings. To insure bonding of fresh concrete with old one, a polymer bonding agent was applied over the exposed surface of the footing. After a curing period, backfilling of fooding with selected material took place to the ground level. 


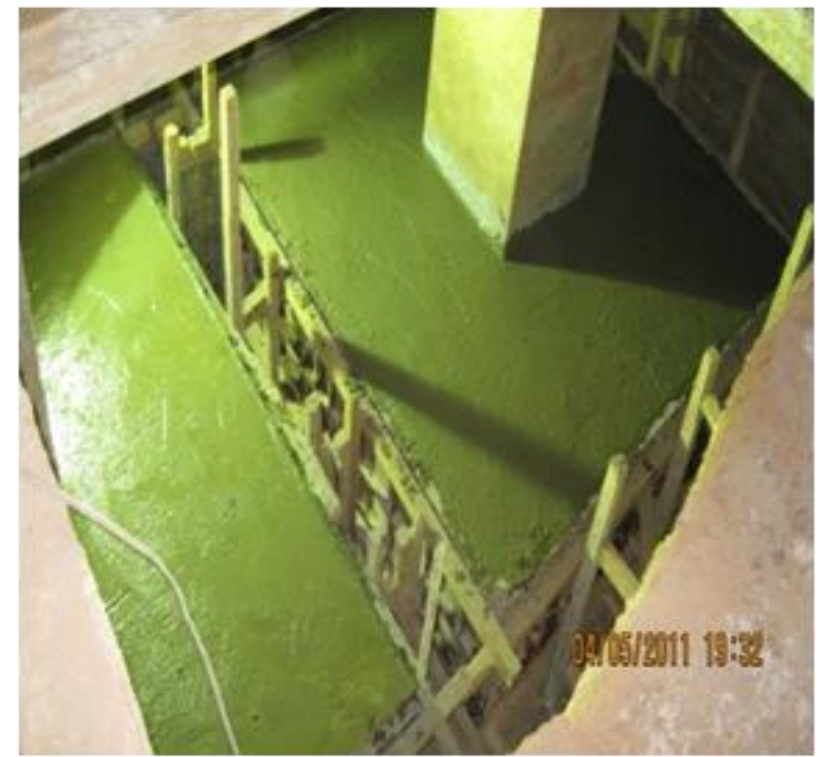

Fig 8. Fresh concrete casted in the enlarged area of the footing

\section{Conclusion}

This paper focused on strengthening of pad footing for storey extension by sectional enlargement. Based on the study findings, the following conclusions can be drawn:

- Results show that the foundation after strengthening is capable to carry extra load from additional storey.

- Strengthening of foundation by sectional enlargement using concrete and steel reinforcement is found to be the most effective and economical strengthening technique to increase the load carrying capacity of existing foundations.

- To enhance bonding of existing concrete with fresh one, footing surface must be painted by epoxy agent. Also, shear connectors must be covered by bonding agents to guarantee fixation in old concrete.

- Experimental and analytical investigations are required to provide further information on the material, strength, and behavior of reinforced concrete structure.

\section{References}

Bian, Y., Hutchinson, T. C., Wilson, D., \& Laefer, D. F. (2006). Grouted helical piers for use in foundation rehabilitation: centrifuge testing. In Paper presented at the International Conference on Re-use of Foundations for Urban Sites (RuFUS). 19-20 October, 2006, Watford, UK. BRE Press..

Branco, F. \& Silva, V. D. (2003). Structural rehabilitation of columns with reinforced concrete jacketing. No. February 2003, pp. 29-37.

British Standard (BS) (1997). Structural use of concrete, Vol. 3. BS 8110-1.

Carolin, A. (2003). Carbon Fibre Reinforced Polymer for Strengthening of Structural Elements, Doctoral Thesis, Division of Structural Engineering, Lulea University of Technology, Lulea.

Cozmanciuc, C., Oltean, R., \& Munteanu, V. (2009). Strengthening techniques of rc columns using fibre reinforced polymeric materials. Buletinul Institutului Politehnic din lasi. Sectia Constructii, Arhitectura, 55(3), 85-92. 
Islam, S., Islam, M. R., Talukder, M. A. Q., \& Hossain, S. R. (2013). Strengthening Technique of Reinforce Concrete Structure: Bangladesh Perspective. American Academic \& Scholarly Research Journal, 5(6), 17-23.

Johansson, B. \& Thyman, M. (2013). Strengthening of buildings for storey extension. Master's Thesis, Department of Civil and Environmental Engineering, Division of Structural Engineering, Chalmers University of Technology, Göteborg, Sweden, p 113

Nordin, H. (2005). Strengthening structures with externally prestressed tendons: literature review, Technical Report, Division of Structural Engineering, Luleå University of Technology, Luleå.

Norris, T., Saadatmanesh, H., \& Ehsani, M. R. (1997). Shear and flexural strengthening of R/C beams with carbon fiber sheets. Journal of structural engineering, 123(7), 903-911.

Rodriguez, M., \& Park, R. (1991). Repair and strengthening of reinforced concrete buildings for seismic resistance. Earthquake Spectra, 7(3), 439-459.

Shihada, S. M., \& Al-Jerjawy, M. (2011). Assessment and Strengthening of a Sixteen Storey RC Building Damaged by Air Attack. The Islamic University Journal, 19(2), 37-56.

Statens, råd förbyggnadsforskning, Förstärkning av betongkonstruktioner (1978). Strengthening of Concrete Structures. In Swedish, Svensk Byggtjänst, Stockholm. 